\title{
Fixed Points Results for $\alpha$-Admissible Mapping of Integral Type on Generalized Metric Spaces
}

\author{
Erdal Karapinar ${ }^{1,2}$ \\ ${ }^{1}$ Department of Mathematics, Atilim University, Incek, 06836 Ankara, Turkey \\ ${ }^{2}$ Nonlinear Analysis and Applied Mathematics Research Group (NAAM), King Abdulaziz University, Jeddah, Saudi Arabia \\ Correspondence should be addressed to Erdal Karapınar; erdalkarapınar@yahoo.com
}

Received 4 June 2014; Accepted 20 July 2014

Academic Editor: Poom Kumam

Copyright (c) 2014 Erdal Karapinar. This is an open access article distributed under the Creative Commons Attribution License, which permits unrestricted use, distribution, and reproduction in any medium, provided the original work is properly cited.

We introduce generalized $(\alpha, \psi)$-contractive mappings of integral type in the context of generalized metric spaces. The results of this paper generalize and improve several results on the topic in literature.

\section{Introduction and Preliminaries}

In fixed point theory, one of the interesting research trends is to investigate the existence and uniqueness of certain mappings in the various abstract spaces. As a result of this approach, the notion of metric has been extended in several ways to get distinct abstract spaces. Among all, we mention the concept of generalized metric space that was introduced by Branciari [1] in 2001. The notion of generalized metric can be considered as a natural extension of the concept of a metric since it is obtained by replacing the the triangle inequality condition by a weaker condition, namely, quadrilateral inequality. Branciari [1] proved Banach's fixed point theorem in such a space. For more details, the reader can refer to $[2-21]$.

At this point, we emphasize why the generalized metric space is interesting. Although the definitions of metric and generalized metric are very close to each other, the topology of the corresponding spaces is very different. In particular, a generalized metric may or may not be continuous. Furthermore, a convergent sequence in generalized metric spaces need not be Cauchy. Besides them, we cannot guarantee that a generalized metric space is Hausdorff, and hence the uniqueness of limits cannot be provided easily.

On the other hand, a notion of $\alpha$-admissible mappings was defined by Samet et al. [22]. By using this notion, the authors introduced $\alpha-\psi$ contractive mappings and investigated the existence and uniqueness of a fixed point of such mappings in the context of metric space. Their results have attracted several authors since they are very interesting and that several existing fixed point theorems listed as consequences of the main result of this paper [22]. The approaches used in this paper have been extended and improved by a number of authors to get similar results in different settings; see, for example, [13, 15, 23-26].

The aim of this paper is to examine the existence and uniqueness of fixed points of $\alpha$-admissible mappings of integral type in the setting of generalized metric spaces. We also underline that the phrase "a generalized metric" has been used for distinct notions since all such concepts generalize the notion of metric. For this reason, when we mention a "generalized metric" we mean the distance function introduced by Branciari [1]. It is evident that any metric space is a generalized metric space but the converse is not true [1].

For the sake of completeness, we recall some basic definitions and notations and fundamental results that will be used in the sequel.

$\mathbb{N}$ and $\mathbb{R}^{+}$denote the set of positive integers and the set of nonnegative reals, respectively. Let $\Psi$ be the family of functions $\psi:[0, \infty) \rightarrow[0, \infty)$ satisfying the following conditions:

(i) $\psi$ is upper semicontinuous;

(ii) $\left(\psi^{n}(t)\right)_{n \in \mathbb{N}}$ converges to 0 as $n \rightarrow \infty$ for all $t>0$;

(iii) $\psi(t)<t$, for any $t>0$. 
In the following, we recall the notion of a generalized metric space.

Definition 1 (see [1]). Let $X$ be a nonempty set and let as $d$ : $X \times X \rightarrow[0, \infty]$ satisfy the following conditions for all $x, y \in$ $X$ and all distinct $u, v \in X$ each of which is different from $x$ and $y$. Consider

$$
\begin{array}{ll}
\text { (GMS1) } & d(x, y)=0 \text { if and only if } x=y \\
\text { (GMS2) } & d(x, y)=d(y, x) \\
\text { (GMS3) } & d(x, y) \leq d(x, u)+d(u, v)+d(v, y) .
\end{array}
$$

Then, the map $d$ is called a generalized metric and abbreviated as GMS. Here, the pair $(X, d)$ is called a generalized metric space.

In the above definition, if $d$ satisfies only (GMS1) and (GMS2), then it is called a semimetric (see, e.g., [27]).

The concepts of convergence, Cauchy sequence, completeness, and continuity on a GMS are defined below.

\section{Definition 2.}

(1) A sequence $\left\{x_{n}\right\}$ in a GMS $(X, d)$ is GMS convergent to a limit $x$ if and only if $d\left(x_{n}, x\right) \rightarrow 0$ as $n \rightarrow \infty$.

(2) A sequence $\left\{x_{n}\right\}$ in a GMS $(X, d)$ is GMS Cauchy if and only if for every $\varepsilon>0$ there exists positive integer $N(\varepsilon)$ such that $d\left(x_{n}, x_{m}\right)<\varepsilon$ for all $n>m>N(\varepsilon)$.

(3) A GMS $(X, d)$ is called complete if every GMS Cauchy sequence in $X$ is GMS convergent.

(4) A mapping $T:(X, d) \rightarrow(X, d)$ is continuous if for any sequence $\left\{x_{n}\right\}$ in $X$ for which $\lim _{n \rightarrow \infty} d\left(x_{n}, x\right)=$ 0 , we have $\lim _{n \rightarrow \infty} d\left(T x_{n}, T x\right)=0$.

The following assumption was suggested by Wilson [27] to replace the triangle inequality with the weakened condition.

(W): for each pair of (distinct) points $u, v$, there is a number $r_{u, v}>0$ such that for every $z \in X$

$$
r_{u, v}<d(u, z)+d(z, v) .
$$

Proposition 3 (see [28]). In a semimetric space, the assumption $(W)$ is equivalent to the assertion that limits are unique.

Proposition 4 (see [28]). Suppose that $\left\{x_{n}\right\}$ is a Cauchy sequence in a GMS $(X, d)$ with $\lim _{n \rightarrow \infty} d\left(x_{n}, u\right)=0$, where $u \in X$. Then $\lim _{n \rightarrow \infty} d\left(x_{n}, z\right)=d(u, z)$ for all $z \in X$. In particular, the sequence $\left\{x_{n}\right\}$ does not converge to $z$ if $z \neq u$.

The following concepts were defined by Samet et al. [22].

Definition 5 (see [22]). For a nonempty set $X$, let $T: X \rightarrow X$ and $\alpha: X \times X \rightarrow[0, \infty)$ be mappings. We say that $T$ is $\alpha$ admissible if for all $x, y \in X$, one has

$$
\alpha(x, y) \geq 1 \Longrightarrow \alpha(T x, T y) \geq 1 \text {. }
$$

In what follows we recall the notion of a $\alpha-\psi$ contractive mapping.

Definition 6 (see [22]). Let $(X, d)$ be a metric space and let $T: X \rightarrow X$ be a given mapping. One says that $T$ is a $\alpha-\psi$ contractive mapping if there exist two functions $\alpha: X \times X \rightarrow$ $[0, \infty)$ and a certain $\psi$ such that

$$
\alpha(x, y) d(T x, T y) \leq \psi(d(x, y)), \quad \forall x, y \in X .
$$

Notice that any contractive mapping, that is a mapping satisfying the Banach contraction, is a $\alpha-\psi$ contractive mapping with $\alpha(x, y)=1$ for all $x, y \in X$ and $\psi(t)=k t$, $k \in(0,1)$.

Inspired by the results of Samet et al. [22], Karapınar [13] gave the analog of the notion of a $\alpha-\psi$ contractive mapping in the context of generalized metric spaces as follows.

Definition 7. Let $(X, d)$ be a generalized metric space and let $T: X \rightarrow X$ be a given mapping. One says that $T$ is a $\alpha-\psi$ contractive mapping if there exist two functions $\alpha: X \times X \rightarrow$ $[0, \infty)$ and a certain $\psi$ such that

$$
\alpha(x, y) d(T x, T y) \leq \psi(d(x, y)), \quad \forall x, y \in X .
$$

Let $(X, d)$ be a generalized metric space. A sequence $\left\{x_{n}\right\}$ is called regular if $\left\{x_{n}\right\}$ is a sequence in $X$ such that $\alpha\left(x_{n}, x_{n+1}\right) \geq 1$ for all $n$ and $x_{n} \rightarrow x \in X$ as $n \rightarrow \infty$; then $\alpha\left(x_{n}, x\right) \geq 1$ for all $n$.

Karapinar [13] also stated the following fixed point theorems.

Theorem 8. Let $(X, d)$ be a complete generalized metric space and let $T: X \rightarrow X$ be a $\alpha-\psi$ contractive mapping. Suppose that

(i) $T$ is $\alpha$-admissible;

(ii) there exists $x_{0} \in X$ such that $\alpha\left(x_{0}, T x_{0}\right) \geq 1$ and $\alpha\left(x_{0}\right.$, $\left.T^{2} x_{0}\right) \geq 1$

(iii) either $T$ is continuous or $\left\{x_{n}\right\}$ is regular.

Then there exists a $u \in X$ such that $T u=u$.

For the uniqueness, an additional condition was considered.

$(U)$ : for all $x, y \in \operatorname{Fix}(T)$, one has $\alpha(x, y) \geq 1$, where $\operatorname{Fix}(T)$ denotes the set of fixed points of $T$.

Theorem 9. Adding condition $(U)$ to the hypotheses of Theorem 8, one obtains that $u$ is the unique fixed point of $T$.

As an alternative condition for the uniqueness of a fixed point of a $\alpha-\psi$ contractive mapping, one will consider the following hypothesis.

(H): for all $x, y \in \operatorname{Fix}(T)$, there exists $z \in X$ such that $\alpha(x, z) \geq 1$ and $\alpha(y, z) \geq 1$.

Theorem 10. Adding conditions $(H)$ and $(W)$ to the hypotheses of Theorem 8 , one obtains that $u$ is the unique fixed point of $T$. 
Corollary 11. Adding condition $(H)$ to the hypotheses of Theorem 8 and assuming that $(X, d)$ is Hausdorff, one obtains that $u$ is the unique fixed point of $T$.

\section{Main Results}

In this section, we will present our main results. For this purpose, we first define the following class of functions: $\Phi=\{\varphi$ : $\left.\varphi: \mathbb{R}^{+} \rightarrow \mathbb{R}\right\}$ such that $\varphi$ is nonnegative, Lebesgue integrable and satisfies

$$
\int_{0}^{\epsilon} \varphi(t) d t>0 \quad \text { for each } \epsilon>0
$$

Definition 12 (see [29]). One says that $\phi \in \Phi$ is an integral subadditive if for each $a, b>0$, one has

$$
\int_{0}^{a+b} \phi(t) d t \leq \int_{0}^{a} \phi(t) d t+\int_{0}^{b} \phi(t) d t .
$$

One denotes by $\Phi_{s}$ the class of all integral subadditive functions $\phi \in \Phi$.

Example 13 (see [29]). Let $\phi_{1}(t)=(1 / 2)(t+1)^{-1 / 2}$ for all $t \geq 0$, $\phi_{2}(t)=(2 / 3)(t+1)^{-1 / 3}$ for all $t \geq 0$, and $\phi_{3}(t)=e^{-t}$ for all $t \geq 0$. Then $\phi_{i} \in \Phi_{s}$, where $i=1,2,3$.

In what follows we introduce notions of generalized $\alpha-\psi$ contractive type mappings of integral type I and type II.

Definition 14. Let $(X, d)$ be a generalized metric space and let $T: X \rightarrow X$ be a given mapping. One says that $T$ is generalized $\alpha-\psi$-contractive type mappings of integral type I if there exist two functions $\alpha: X \times X \rightarrow[0,+\infty)$ and $\psi \in \Psi$ such that for each $x, y \in X$

$$
\alpha(x, y) \int_{0}^{d(T x, T y)} \varphi(t) d t \leq \psi\left(\int_{0}^{M(x, y)} \varphi(t) d t\right),
$$

where $\varphi \in \Phi_{s}$ and

$$
M(x, y)=\max \{d(x, y), d(x, T x), d(y, T y)\} .
$$

Definition 15. Let $(X, d)$ be a generalized metric space and let $T: X \rightarrow X$ be a given mapping. One says that $T$ is generalized $\alpha-\psi$-contractive type mappings of integral type II if there exist two functions $\alpha: X \times X \rightarrow[0,+\infty)$ and $\psi \in \Psi$ such that for each $x, y \in X$

$$
\alpha(x, y) \int_{0}^{d(T x, T y)} \varphi(t) d t \leq \psi\left(\int_{0}^{N(x, y)} \varphi(t) d t\right)
$$

where $\varphi \in \Phi_{s}$ and

$$
N(x, y)=\max \left\{d(x, y), \frac{d(x, T x)+d(y, T y)}{2}\right\} .
$$

Now, we state our first fixed point result.

Theorem 16. Let $(X, d)$ be a complete generalized metric space and let $T: X \rightarrow X$ be a generalized $\alpha-\psi$-contractive type mappings of integral type I. Suppose that

(i) $T$ is $\alpha$-admissible; (ii) there exists $x_{0} \in X$ such that $\alpha\left(x_{0}, T x_{0}\right) \geq 1$ and $\alpha\left(x_{0}, T^{2} x_{0}\right) \geq 1$;

(iii) $T$ is continuous.

Then there exists a $u \in X$ such that $T u=u$.

Proof. Regarding assumption (ii), we guarantee that there exists a point $x_{0} \in X$ such that $\alpha\left(x_{0}, T x_{0}\right) \geq 1$ and $\alpha\left(x_{0}\right.$, $\left.T^{2} x_{0}\right) \geq 1$. Starting this initial value $x_{0} \in X$, we define an iterative sequence $\left\{x_{n}\right\}$ in $X$ as follows:

$$
x_{n+1}=T x_{n}=T^{n+1} x_{0} \quad \forall n \geq 0 .
$$

Notice that if $x_{n_{0}}=x_{n_{0}+1}$ for some $n_{0}$, then the proof is completed in this case. Indeed, we have $u=x_{n_{0}}=x_{n_{0}+1}=$ $T x_{n_{0}}=T u$. As a consequence of this observation, throughout the proof, we assume that

$$
x_{n} \neq x_{n+1} \quad \forall n .
$$

It is evident that

$$
\begin{aligned}
\alpha\left(x_{0}, x_{1}\right) & =\alpha\left(x_{0}, T x_{0}\right) \geq 1 \\
& \Longrightarrow \alpha\left(T x_{0}, T x_{1}\right)=\alpha\left(x_{1}, x_{2}\right) \geq 1,
\end{aligned}
$$

since $T$ is $\alpha$-admissible. Recursively, we find that

$$
\alpha\left(x_{n}, x_{n+1}\right) \geq 1, \quad \forall n=0,1, \ldots
$$

By repeating the same arguments, used above, we also derive that

$$
\begin{aligned}
\alpha\left(x_{0}, x_{2}\right) & =\alpha\left(x_{0}, T^{2} x_{0}\right) \geq 1 \\
& \Longrightarrow \alpha\left(T x_{0}, T x_{2}\right)=\alpha\left(x_{1}, x_{3}\right) \geq 1
\end{aligned}
$$

From the previous inequalities, we conclude that

$$
\alpha\left(x_{n}, x_{n+2}\right) \geq 1, \quad \forall n=0,1, \ldots
$$

We divide the proofs into 4 steps.

Step 1. We show that

$$
\lim _{n \rightarrow \infty} d\left(x_{n}, x_{n+1}\right)=0 .
$$

By taking (8) and (15) into account, we obtain that

$$
\begin{aligned}
\int_{0}^{d\left(x_{n}, x_{n+1}\right)} \varphi(t) d t & =\int_{0}^{d\left(T x_{n-1}, T x_{n}\right)} \varphi(t) d t \\
& \leq \alpha\left(x_{n-1}, x_{n}\right) \int_{0}^{d\left(T x_{n-1}, T x_{n}\right)} \varphi(t) d t \\
& \leq \psi\left(\int_{0}^{M\left(x_{n-1}, x_{n}\right)} \varphi(t) d t\right)
\end{aligned}
$$

for all $n \geq 1$, where

$$
\begin{aligned}
M & \left(x_{n-1}, x_{n}\right) \\
& =\max \left\{d\left(x_{n-1}, x_{n}\right), d\left(x_{n-1}, T x_{n-1}\right), d\left(x_{n}, T x_{n}\right)\right\} \\
& =\max \left\{d\left(x_{n-1}, x_{n}\right), d\left(x_{n-1}, x_{n}\right), d\left(x_{n}, x_{n+1}\right)\right\} \\
& =\max \left\{d\left(x_{n-1}, x_{n}\right), d\left(x_{n}, x_{n+1}\right)\right\} .
\end{aligned}
$$


If we have $M\left(x_{n-1}, x_{n}\right)=d\left(x_{n}, x_{n+1}\right)$ for some $n \in \mathbb{N}$, then inequality (19) turns into

$$
\begin{aligned}
\int_{0}^{d\left(x_{n}, x_{n+1}\right)} \varphi(t) d t & \leq \psi\left(\int_{0}^{M\left(x_{n-1}, x_{n}\right)} \varphi(t) d t\right) \\
& =\psi\left(\int_{0}^{d\left(x_{n}, x_{n+1}\right)} \varphi(t) d t\right) \\
& <\int_{0}^{d\left(x_{n}, x_{n+1}\right)} \varphi(t) d t
\end{aligned}
$$

by regarding the property (iii) of the auxiliary function $\psi$. This is a contradiction. Consequently, we have $M\left(x_{n-1}, x_{n}\right)=$ $d\left(x_{n-1}, x_{n}\right)$ for all $n \in \mathbb{N}$ and (19) becomes

$$
\int_{0}^{d\left(x_{n}, x_{n+1}\right)} \varphi(t) d t \leq \psi\left(\int_{0}^{d\left(x_{n-1}, x_{n}\right)} \varphi(t) d t\right) \quad \forall n \in \mathbb{N} .
$$

This yields that

$$
\int_{0}^{d\left(x_{n}, x_{n+1}\right)} \varphi(t) d t<\int_{0}^{d\left(x_{n-1}, x_{n}\right)} \varphi(t) d t \quad \forall n \in \mathbb{N},
$$

by recalling the property (iii) of the auxiliary function $\psi$. Due to $(22)$, we find that

$$
\int_{0}^{d\left(x_{n}, x_{n+1}\right)} \varphi(t) d t \leq \psi^{n}\left(\int_{0}^{d\left(x_{0}, x_{1}\right)} \varphi(t) d t\right), \quad \forall n \in \mathbb{N} .
$$

By property of $\psi$ again, we deduce that

$$
\lim _{n \rightarrow \infty} \int_{0}^{d\left(x_{n}, x_{n+1}\right)} \varphi(t) d t=0,
$$

and hence

$$
\lim _{n \rightarrow \infty} d\left(x_{n}, x_{n+1}\right)=0 .
$$

Step 2. We show that

$$
\lim _{n \rightarrow \infty} d\left(x_{n}, x_{n+2}\right)=0 .
$$

Combining (8) and (17), we conclude that

$$
\begin{aligned}
\int_{0}^{d\left(x_{n}, x_{n+2}\right)} \varphi(t) d t & =\int_{0}^{d\left(T x_{n-1}, T x_{n+1}\right)} \varphi(t) d t \\
& \leq \alpha\left(x_{n-1}, x_{n+1}\right) \int_{0}^{d\left(T x_{n-1}, T x_{n+1}\right)} \varphi(t) d t \\
& \leq \psi\left(\int_{0}^{M\left(x_{n-1}, x_{n+1}\right)} \varphi(t) d t\right),
\end{aligned}
$$

for all $n \geq 1$, where

$$
\begin{aligned}
M & \left(x_{n-1}, x_{n+1}\right) \\
& =\max \left\{d\left(x_{n-1}, x_{n+1}\right), d\left(x_{n-1}, T x_{n-1}\right), d\left(x_{n+1}, T x_{n+1}\right)\right\} \\
& =\max \left\{d\left(x_{n-1}, x_{n+1}\right), d\left(x_{n-1}, x_{n}\right), d\left(x_{n+1}, x_{n+2}\right)\right\} .
\end{aligned}
$$

By (23), we have

$$
\begin{aligned}
M\left(x_{n-1}, x_{n+1}\right) & =\max \left\{d\left(x_{n-1}, x_{n+1}\right), d\left(x_{n-1}, x_{n}\right)\right\} \\
& =\max \left\{e_{n}, d_{n}\right\},
\end{aligned}
$$

where $e_{n}=d\left(x_{n}, x_{n+2}\right)$ and $d_{n}=d\left(x_{n}, x_{n+1}\right)$. Thus, inequality (28) can be considered as

$$
\begin{aligned}
\int_{0}^{e_{n}} \varphi(t) d t & =\int_{0}^{d\left(x_{n}, x_{n+2}\right)} \varphi(t) d t \leq \psi\left(\int_{0}^{M\left(x_{n-1}, x_{n+1}\right)} \varphi(t) d t\right) \\
& =\psi\left(\int_{0}^{\max \left\{e_{n-1}, d_{n-1}\right\}} \varphi(t) d t\right) \quad \forall n \in \mathbb{N} .
\end{aligned}
$$

On the other hand, by (23)

$$
\int_{0}^{d_{n}} \varphi(t) d t \leq \int_{0}^{d_{n-1}} \varphi(t) d t \leq \int_{0}^{\max \left\{e_{n-1}, d_{n-1}\right\}} \varphi(t) d t
$$

Therefore,

$$
\int_{0}^{\max \left\{e_{n}, d_{n}\right\}} \varphi(t) d t \leq \int_{0}^{\max \left\{e_{n-1}, d_{n-1}\right\}} \varphi(t) d t \quad \forall n \in \mathbb{N}
$$

Then, the sequence $\left\{\int_{0}^{\max \left\{e_{n}, d_{n}\right\}} \varphi(t) d t\right\}$ is monotone nonincreasing, so it converges to some $t \geq 0$. Assume that $L>0$. Now, by (18)

$$
\begin{aligned}
\limsup _{n \rightarrow \infty} \int_{0}^{e_{n}} \varphi(t) d t & =\limsup _{n \rightarrow \infty} \int_{0}^{\max \left\{e_{n}, d_{n}\right\}} \varphi(t) d t \\
& =\lim _{n \rightarrow \infty} \int_{0}^{\max \left\{e_{n}, d_{n}\right\}} \varphi(t) d t=L .
\end{aligned}
$$

Taking $n \rightarrow \infty$ in (31)

$$
\begin{aligned}
L & =\limsup _{n \rightarrow \infty} \int_{0}^{e_{n}} \varphi(t) d t \\
& \leq \limsup _{n \rightarrow \infty}\left(\int_{0}^{\max \left\{e_{n-1}, d_{n-1}\right\}} \varphi(t) d t\right) \\
& \leq \psi\left(\lim _{n \rightarrow \infty} \int_{0}^{\max \left\{e_{n-1}, d_{n-1}\right\}} \varphi(t) d t\right)=\psi(L)<L,
\end{aligned}
$$

which is a contradiction; that is, (27) is proved.

Step 3. We will prove that

$$
x_{n} \neq x_{m} \quad \forall n \neq m \text {. }
$$

We argue by contradiction. Suppose that $x_{n}=x_{m}$ for some $m, n \in \mathbb{N}$ with $m \neq n$. Since $d\left(x_{p}, x_{p+1}\right)>0$ for each $p \in \mathbb{N}$, 
so without loss of generality, assume that $m>n+1$. Consider now

$$
\begin{aligned}
\int_{0}^{d\left(x_{n}, x_{n+1}\right)} \varphi(t) d t & =\int_{0}^{d\left(x_{n}, T x_{n}\right)} \varphi(t) d t \\
& =\int_{0}^{d\left(x_{m}, T x_{m}\right)} \varphi(t) d t \\
& =\int_{0}^{d\left(T x_{m-1}, T x_{m}\right)} \varphi(t) d t \\
& \leq \alpha\left(x_{m-1}, x_{m}\right) \int_{0}^{d\left(T x_{m-1}, T x_{m}\right)} \varphi(t) d t \\
& \leq \psi\left(\int_{0}^{M\left(x_{m-1}, x_{m}\right)} \varphi(t) d t\right),
\end{aligned}
$$

where

$$
\begin{aligned}
M & \left(x_{m-1}, x_{m}\right) \\
& =\max \left\{d\left(x_{m-1}, x_{m}\right), d\left(x_{m-1}, T x_{m-1}\right), d\left(x_{m}, T x_{m}\right)\right\} \\
& =\max \left\{d\left(x_{m-1}, x_{m}\right), d\left(x_{m-1}, x_{m}\right), d\left(x_{m}, x_{m+1}\right)\right\} \\
& =\max \left\{d\left(x_{m-1}, x_{m}\right), d\left(x_{m}, x_{m+1}\right)\right\} .
\end{aligned}
$$

If $M\left(x_{m-1}, x_{m}\right)=d\left(x_{m-1}, x_{m}\right)$, then from (37) we get that

$$
\begin{aligned}
\int_{0}^{d\left(x_{n}, x_{n+1}\right)} \varphi(t) d t & =\int_{0}^{d\left(x_{n}, T x_{n}\right)} \varphi(t) d t \\
& =\int_{0}^{d\left(x_{m}, T x_{m}\right)} \varphi(t) d t \\
& =\int_{0}^{d\left(x_{m}, x_{m+1}\right)} \varphi(t) d t \\
& \leq \alpha\left(x_{m}, x_{m+1}\right) \int_{0}^{d\left(T x_{m-1}, T x_{m}\right)} \varphi(t) d t \\
& \leq \psi\left(\int_{0}^{M\left(x_{m-1}, x_{m}\right)} \varphi(t) d t\right) \\
& =\psi\left(\int_{0}^{d\left(x_{m-1}, x_{m}\right)} \varphi(t) d t\right) \\
& \leq \psi
\end{aligned}
$$

If $M\left(x_{m-1}, x_{m}\right)=d\left(x_{m}, x_{m+1}\right)$, inequality (37) becomes

$$
\begin{aligned}
\int_{0}^{d\left(x_{n}, x_{n+1}\right)} \varphi(t) d t & =\int_{0}^{d\left(x_{n}, T x_{n}\right)} \varphi(t) d t \\
& =\int_{0}^{d\left(x_{m}, T x_{m}\right)} \varphi(t) d t
\end{aligned}
$$

$$
\begin{aligned}
& =\int_{0}^{d\left(T x_{m-1}, T x_{m}\right)} \varphi(t) d t \\
& \leq \alpha\left(x_{m-1}, x_{m}\right) \int_{0}^{d\left(T x_{m-1}, T x_{m}\right)} \varphi(t) d t \\
& \leq \psi\left(\int_{0}^{M\left(x_{m-1}, x_{m}\right)} \varphi(t) d t\right) \\
& =\psi\left(\int_{0}^{d\left(x_{m}, x_{m+1}\right)} \varphi(t) d t\right) \\
& \leq \psi^{m-n+1}\left(\int_{0}^{d\left(x_{n}, x_{n+1}\right)} \varphi(t) d t\right) .
\end{aligned}
$$

Due to a property of $\psi$, inequalities (39) and (40) together yield that

$$
\begin{aligned}
\int_{0}^{d\left(x_{n}, x_{n+1}\right)} \varphi(t) d t & \leq \psi^{m-n}\left(\int_{0}^{d\left(x_{n}, x_{n+1}\right)} \varphi(t) d t\right) \\
& <\int_{0}^{d\left(x_{n}, x_{n+1}\right)} \varphi(t) d t, \\
\int_{0}^{d\left(x_{n}, x_{n+1}\right)} \varphi(t) d t & \leq \psi^{m-n+1}\left(\int_{0}^{d\left(x_{n}, x_{n+1}\right)} \varphi(t) d t\right) \\
& <\int_{0}^{d\left(x_{n}, x_{n+1}\right)} \varphi(t) d t,
\end{aligned}
$$

respectively. In each case, there is a contradiction.

Step 4. We will prove that $\left\{x_{n}\right\}$ is a Cauchy sequence; that is,

$$
\operatorname{Lim}_{n \rightarrow \infty} \int_{0}^{d\left(x_{n}, x_{n+k}\right)} \varphi(t) d t=0 \quad \forall k \in \mathbb{N}
$$

The cases $k=1$ and $k=2$ are proved, respectively, by (18) and (27). Now, take $k \geq 3$ arbitrary. It is sufficient to examine two cases.

Case (I). Suppose that $k=2 m+1$ where $m \geq 1$. Then, by using step 3 and the quadrilateral inequality together with (24), we find

$$
\begin{aligned}
& \int_{0}^{d\left(x_{n}, x_{n+k}\right)} \varphi(t) d t \\
& \quad=\int_{0}^{d\left(x_{n}, x_{n+2 m+1}\right)} \varphi(t) d t \\
& \quad \leq \int_{0}^{d\left(x_{n}, x_{n+1}\right)+d\left(x_{n+1}, x_{n+2}\right)+\cdots+d\left(x_{n+2 m}, x_{n+2 m+1}\right)} \varphi(t) d t
\end{aligned}
$$




$$
\begin{aligned}
\leq & \int_{0}^{d\left(x_{n}, x_{n+1}\right)} \varphi(t)+\int_{0}^{d\left(x_{n+1}, x_{n+2}\right)} \varphi(t) \\
& +\cdots+\int_{0}^{d\left(x_{n+2 m}, x_{n+2 m+1}\right)} \varphi(t) d t \\
\leq & \sum_{p=n}^{n+2 m} \psi^{p}\left(\int_{0}^{d\left(x_{0}, x_{1}\right)} \varphi(t) d t\right) \\
\leq & \sum_{p=n}^{+\infty} \psi^{p}\left(\int_{0}^{d\left(x_{0}, x_{1}\right)} \varphi(t) d t\right) \rightarrow 0 \text { as } n \rightarrow \infty .
\end{aligned}
$$

Case (II). Suppose that $k=2 m$ where $m \geq 2$. Again, by applying the quadrilateral inequality and step 3 together with (24), we find

$$
\begin{aligned}
\int_{0}^{d\left(x_{n}, x_{n+k}\right)} \varphi(t) d t & \int_{0}^{d\left(x_{n}, x_{n+2 m}\right)} \varphi(t) d t \\
\quad \leq & \int_{0}^{d\left(x_{n}, x_{n+2}\right)+d\left(x_{n+2}, x_{n+3}\right)+\cdots+d\left(x_{n+2 m-1}, x_{n+2 m}\right)} \varphi(t) d t \\
\leq & \int_{0}^{d\left(x_{n}, x_{n+2}\right)} \varphi(t) d t+\int_{0}^{d\left(x_{n+2}, x_{n+3}\right)} \varphi(t) d t \\
& +\cdots+\int_{0}^{d\left(x_{n+2 m-1}, x_{n+2 m}\right)} \varphi(t) d t \\
\leq & \int_{0}^{d\left(x_{n}, x_{n+2}\right)} \varphi(t) d t+\sum_{p=n+2}^{n+2 m-1} \psi^{p}\left(\int_{0}^{d\left(x_{0}, x_{1}\right)} \varphi(t) d t\right) \\
\leq & \left.\int_{0}^{d\left(x_{n}, x_{n+2}\right)} \varphi(t) d t \sum_{p=n}^{\longrightarrow} \text { as } n \longrightarrow \infty(t) d t\right) \\
& +\sum_{p=n}^{+\infty} \psi^{p}\left(\int_{0}^{d\left(x_{0}, x_{1}\right)} \varphi(t)\right.
\end{aligned}
$$

By combining expressions (44) and (45), we have

$$
\lim _{n \rightarrow \infty} \int_{0}^{d\left(x_{n}, x_{n+k}\right)} \varphi(t) d t=0 \quad \forall k \geq 3 .
$$

Hence, we have

$$
\lim _{n \rightarrow \infty} d\left(x_{n}, x_{n+k}\right)=0 \quad \forall k \geq 3 .
$$

We conclude that $\left\{x_{n}\right\}$ is a Cauchy sequence in $(X, d)$. Since $(X, d)$ is complete, there exists $u \in X$ such that

$$
\lim _{n \rightarrow \infty} d\left(x_{n}, u\right)=0 \text {. }
$$

Since $T$ is continuous, we obtain from (48) that

$$
\lim _{n \rightarrow \infty} d\left(x_{n+1}, T u\right)=\lim _{n \rightarrow \infty} d\left(T x_{n}, T u\right)=0 ;
$$

that is, $\lim _{n \rightarrow \infty} x_{n+1}=T u$. Taking Proposition 4 into account, we conclude that $T u=u$; that is, $u$ is a fixed point of T.
The following result is deduced from Theorem 16 due to the obvious inequality $N(x, y) \leq M(x, y)$.

Theorem 17. Let $(X, d)$ be a complete generalized metric space and let $T: X \rightarrow X$ be generalized $\alpha-\psi$-contractive type mappings of integral type II. Suppose that

(i) $T$ is $\alpha$-admissible;

(ii) there exists $x_{0} \in X$ such that $\alpha\left(x_{0}, T x_{0}\right) \geq 1$ and $\alpha\left(x_{0}, T^{2} x_{0}\right) \geq 1$

(iii) $T$ is continuous.

Then there exists a $u \in X$ such that $T u=u$.

Theorem 16 remains true if we replace the continuity hypothesis by the following property.

If $\left\{x_{n}\right\}$ is a sequence in $X$ such that $\alpha\left(x_{n}, x_{n+1}\right) \geq 1$ for all $n$ and $x_{n} \rightarrow x \in X$ as $n \rightarrow \infty$, then there exists a subsequence $\left\{x_{n(k)}\right\}$ of $\left\{x_{n}\right\}$ such that $\alpha\left(x_{n(k)}, x\right) \geq 1$ for all $k$.

This statement is given as follows.

Theorem 18. Let $(X, d)$ be a complete generalized metric space and let $T: X \rightarrow X$ be generalized $\alpha-\psi$-contractive type mappings of integral type I. Suppose that

(i) $T$ is $\alpha$-admissible;

(ii) there exists $x_{0} \in X$ such that $\alpha\left(x_{0}, T x_{0}\right) \geq 1$ and $\alpha\left(x_{0}, T^{2} x_{0}\right) \geq 1$

(iii) if $\left\{x_{n}\right\}$ is a sequence in $X$ such that $\alpha\left(x_{n}, x_{n+1}\right) \geq 1$ for all $n$ and $x_{n} \rightarrow x \in X$ as $n \rightarrow \infty$, then there exists a subsequence $\left\{x_{n(k)}\right\}$ of $\left\{x_{n}\right\}$ such that $\alpha\left(x_{n(k)}, x\right) \geq 1$ for all $k$.

Then, there exists $u \in X$ such that $T u=u$.

Proof. Following the lines in the proof of Theorem 8, we deduce that the sequence $\left\{x_{n}\right\}$ defined by $x_{n+1}=T x_{n}$ for all $n \geq 0$ is Cauchy and converges to some $u \in X$. In view of Proposition 4,

$$
\lim _{k \rightarrow \infty} d\left(x_{n(k)+1}, T u\right)=d(u, T u) .
$$

By using the method of reductio ad absurdum, we will show that $T u=u$. Suppose, on the contrary, that $T u \neq u$; that is, $d(T u, u)>0$. From (15) and condition (iii), there exists a subsequence $\left\{x_{n(k)}\right\}$ of $\left\{x_{n}\right\}$ such that $\alpha\left(x_{n(k)}, u\right) \geq 1$ for all $k$.

By applying (8), we find that

$$
\begin{aligned}
\int_{0}^{d\left(x_{n(k)+1}, T u\right)} \varphi(t) d t & \leq \alpha\left(x_{n(k)}, u\right) \int_{0}^{d\left(T x_{n(k)}, T u\right)} \varphi(t) d t \\
& \leq \psi\left(\int_{0}^{M\left(x_{n(k)}, u\right)} \varphi(t) d t\right),
\end{aligned}
$$

where

$$
\begin{aligned}
M & \left(x_{n(k)}, u\right) \\
& =\max \left\{d\left(x_{n(k)}, u\right), d\left(x_{n(k)}, T x_{n(k)}\right), d(u, T u)\right\} \\
& =\max \left\{d\left(x_{n(k)}, u\right), d\left(x_{n(k)}, x_{n(k)+1}\right), d(u, T u)\right\} .
\end{aligned}
$$


By (18) and (50), we obtain

$$
\operatorname{Lim}_{k \rightarrow \infty} \int_{0}^{M\left(x_{n(k)}, u\right)} \varphi(t) d t=\int_{0}^{d(u, T u)} \varphi(t) d t
$$

Since $\psi$ is upper semicontinuous, by letting $k \rightarrow \infty$ in (51) we derive that

$$
\int_{0}^{d(u, T u)} \varphi(t) d t \leq \psi\left(\int_{0}^{d(u, T u)} \varphi(t) d t\right)<\int_{0}^{d(u, T u)} \varphi(t) d t .
$$

This is a contradiction. Hence, we obtain that $u$ is a fixed point of $T$; that is, $T u=u$.

In the following, the hypothesis of upper semicontinuity of $\psi$ is not required. Similar to Theorem 18, for the generalized $\alpha-\psi$ contractive mappings of type II, we have the following.

Theorem 19. Let $(X, d)$ be a complete generalized metric space and let $T: X \rightarrow X$ be generalized $\alpha-\psi$-contractive type mappings of integral type II. Suppose that

(i) $T$ is $\alpha$-admissible;

(ii) there exists $x_{0} \in X$ such that $\alpha\left(x_{0}, T x_{0}\right) \geq 1$ and $\alpha\left(x_{0}, T^{2} x_{0}\right) \geq 1$;

(iii) if $\left\{x_{n}\right\}$ is a sequence in $X$ such that $\alpha\left(x_{n}, x_{n+1}\right) \geq 1$ for all $n$ and $x_{n} \rightarrow x \in X$ as $n \rightarrow \infty$, then there exists a subsequence $\left\{x_{n(k)}\right\}$ of $\left\{x_{n}\right\}$ such that $\alpha\left(x_{n(k)}, x\right) \geq 1$ for all $k$.

Then, there exists $u \in X$ such that $T u=u$.

Proof. Following the proof of Theorem 17 (which is the same as Theorem 16), we know that the sequence $\left\{x_{n}\right\}$ defined by $x_{n+1}=T x_{n}$ for all $n \geq 0$ is Cauchy and converges to some $u \in X$. Similarly, in view of Proposition 4,

$$
\lim _{k \rightarrow \infty} d\left(x_{n(k)+1}, T u\right)=d(u, T u)
$$

We will show that $T u=u$. Suppose, on the contrary, that $T u \neq$ $u$. From (15) and condition (iii), there exists a subsequence $\left\{x_{n(k)}\right\}$ of $\left\{x_{n}\right\}$ such that $\alpha\left(x_{n(k)}, u\right) \geq 1$ for all $k$. By applying (10), for all $k$, we get that

$$
\begin{aligned}
\int_{0}^{d\left(x_{n(k)+1}, T u\right)} \varphi(t) d t & \leq \alpha\left(x_{n(k)}, u\right) \int_{0}^{d\left(T x_{n(k)}, T u\right)} \varphi(t) d t \\
& \leq \psi\left(\int_{0}^{N\left(x_{n(k)}, u\right)} \varphi(t) d t\right),
\end{aligned}
$$

where

$$
\begin{aligned}
& N\left(x_{n(k)}, u\right) \\
& \quad=\max \left\{d\left(x_{n(k)}, u\right), \frac{d\left(x_{n(k)}, T x_{n(k)}\right)+d(u, T u)}{2}\right\} .
\end{aligned}
$$

Letting $k \rightarrow \infty$ in (56), we have

$$
\lim _{k \rightarrow \infty} \int_{0}^{N\left(x_{n(k)}, u\right)} \varphi(t) d t=\int_{0}^{d(u, T u) / 2} \varphi(t) d t
$$

From (58), for $k$ large enough, we have $N\left(x_{n(k)}, u\right)>0$, which implies that

$$
\psi\left(\int_{0}^{N\left(x_{n(k)}, u\right)} \varphi(t) d t\right)<\int_{0}^{N\left(x_{n(k)}, u\right)} \varphi(t) d t
$$

Thus, from (56) and (58), we have

$$
\int_{0}^{d(u, T u)} \varphi(t) d t \leq \int_{0}^{d(u, T u) / 2} \varphi(t) d t
$$

which is a contradiction. Hence, we obtain that $u$ is a fixed point of $T$; that is, $T u=u$.

Theorem 20. Adding condition $(U)$ to the hypotheses of Theorem 16 (resp., Theorem 18), one obtains that $u$ is the unique fixed point of $T$.

Proof. By using the method of reductio ad absurdum, we will show that $u$ is the unique fixed point of T. Let $v$ be another fixed point of $T$ with $v \neq u$. By hypothesis $(U)$,

$$
1 \leq \alpha(u, v)=\alpha(T u, T v)
$$

Now, due to (8), we have

$$
\begin{aligned}
\int_{0}^{d(u, v)} \varphi(t) d t & \leq \alpha(u, v) \int_{0}^{d(u, v)} \varphi(t) d t \\
& =\alpha(T u, T v) \int_{0}^{d(T u, T v)} \varphi(t) d t \\
& \leq \psi\left(\int_{0}^{M(u, v)} \varphi(t) d t\right) \\
& =\psi\left(\int_{0}^{\max \{d(u, v), d(u, T u), d(v, T v)\}} \varphi(t) d t\right) \\
& =\psi\left(\int_{0}^{d(u, v)} \varphi(t) d t\right)<\int_{0}^{d(u, v)} \varphi(t) d t
\end{aligned}
$$

which is a contradiction. Hence, $u=v$.

Theorem 21. Adding condition $(U)$ to the hypotheses of Theorem 17 (resp., Theorem 19), one obtains that $u$ is the unique fixed point of $T$.

Proof. As in Theorem 20, we use the method of reductio ad absurdum to show that $u$ is the unique fixed point of $T$. Suppose, on the contrary, that $v$ is another fixed point of $T$ with $v \neq u$. It is evident that $1 \leq \alpha(u, v)=\alpha(T u, T v)$. 
Now, due to (10), we have

$$
\begin{aligned}
\int_{0}^{d(u, v)} \varphi(t) d t & \leq \alpha(u, v) \int_{0}^{d(u, v)} \varphi(t) d t \\
& =\alpha(T u, T v) \int_{0}^{d(T u, T v)} \varphi(t) d t \\
& \leq \psi\left(\int_{0}^{N(u, v)} \varphi(t) d t\right) \\
& =\psi\left(\int_{0}^{\max \{d(u, v),(d(u, T u)+d(v, T v)) / 2\}} \varphi(t) d t\right) \\
& =\psi\left(\int_{0}^{d(u, v)} \varphi(t) d t\right)<\int_{0}^{d(u, v)} \varphi(t) d t
\end{aligned}
$$

which is a contradiction. Hence, $u=v$.

For the uniqueness of a fixed point of a generalized $\alpha-\psi$ contractive mapping, we will consider the following hypotheses suggested in [11].

(H1): for all $x, y \in \operatorname{Fix}(T)$, there exists $z$ in $X$ such that $\alpha(x, z) \geq 1$ and $\alpha(y, z) \geq 1$.

(H2): let $x, y \in \operatorname{Fix}(T)$. If there exists $\left\{z_{n}\right\}$ in $X$ such that $\alpha\left(x, z_{n}\right) \geq 1$ and $\alpha\left(y, z_{n}\right) \geq 1$, then

$$
d\left(z_{n}, z_{n+1}\right) \leq \inf \left\{d\left(x, z_{n}\right), d\left(y, z_{n}\right)\right\} \quad \forall n \in \mathbb{N} .
$$

Theorem 22. Adding conditions ( $H 1),(H 2)$, and $(W)$ to the hypotheses of Theorem 16 (resp., Theorem 18), one obtains that $u$ is the unique fixed point of $T$.

Proof. We will show that $u$ is the unique fixed point of $T$, by using the method of reductio ad absurdum. Let $v$ be another fixed point of $T$ with $v \neq u$; that is, $d(u, v)>0$. Due to (H1), there exists $z \in X$ such that

$$
\alpha(u, z) \geq 1, \quad \alpha(v, z) \geq 1 .
$$

Since $T$ is $\alpha$-admissible, from (65), we have

$$
\alpha\left(u, T^{n} z\right) \geq 1, \quad \alpha\left(v, T^{n} z\right) \geq 1, \quad \forall n .
$$

Define the sequence $\left\{z_{n}\right\}$ in $X$ by $z_{n+1}=T z_{n}$ for all $n \geq 0$ and $z_{0}=z$. From (66), for all $n$, we have

$$
\begin{aligned}
\int_{0}^{d\left(u, z_{n+1}\right)} \varphi(t) d t & =\int_{0}^{d\left(T u, T z_{n}\right)} \varphi(t) d t \\
& \leq \alpha\left(u, z_{n}\right) \int_{0}^{d\left(T u, T z_{n}\right)} \varphi(t) d t \\
& \leq \psi\left(\int_{0}^{M\left(u, z_{n}\right)} \varphi(t) d t\right),
\end{aligned}
$$

where

$$
\begin{aligned}
M\left(u, z_{n}\right) & =\max \left\{d\left(u, z_{n}\right), d(u, T u), d\left(z_{n}, T z_{n}\right)\right\} \\
& =\max \left\{d\left(u, z_{n}\right), d\left(z_{n}, z_{n+1}\right)\right\} .
\end{aligned}
$$

By $(\mathrm{H} 2)$, we get

$$
M\left(u, z_{n}\right)=d\left(u, z_{n}\right) \quad \forall n .
$$

Iteratively, by using inequality (67), we get that

$$
\int_{0}^{d\left(u, z_{n}\right)} \varphi(t) d t \leq \psi^{n}\left(\int_{0}^{d\left(u, z_{0}\right)} \varphi(t) d t\right),
$$

for all $n$. Letting $n \rightarrow \infty$ in the above inequality, we obtain

$$
\lim _{n \rightarrow \infty} \int_{0}^{d\left(z_{n}, u\right)} \varphi(t) d t=0,
$$

and hence

$$
\lim _{n \rightarrow \infty} d\left(z_{n}, u\right)=0
$$

Similarly, one can show that

$$
\lim _{n \rightarrow \infty} d\left(z_{n}, v\right)=0
$$

Regarding (W), there exists $r_{u, v}>0$ such that for all $n$

$$
r_{u, v}<d\left(u, z_{n}\right)+d\left(v, z_{n}\right)
$$

and hence

$$
\int_{0}^{r_{u, v}} \varphi(t) d t<\int_{0}^{d\left(u, z_{n}\right)+d\left(v, z_{n}\right)} \varphi(t) d t .
$$

From (71) and (73), by passing $n \rightarrow \infty$, it follows that $r_{u, v}=0$, which is a contradiction. Thus, we proved that $u$ is the unique fixed point of $T$.

Theorem 23. Adding conditions (H1), (H2), and $(W)$ to the hypotheses of Theorem 17 (resp., Theorem 19), one obtains that $u$ is the unique fixed point of $T$.

Proof. Suppose that $v$ is another fixed point of $T$ and $u \neq v$. From (H1), there exists $z \in X$ such that

$$
\alpha(u, z) \geq 1, \quad \alpha(v, z) \geq 1
$$

Since $T$ is $\alpha$-admissible, from (76), we have

$$
\alpha\left(u, T^{n} z\right) \geq 1, \quad \alpha\left(v, T^{n} z\right) \geq 1, \quad \forall n .
$$

Define the sequence $\left\{z_{n}\right\}$ in $X$ by $z_{n+1}=T z_{n}$ for all $n \geq 0$ and $z_{0}=z$. From (77), for all $n$, we have

$$
\begin{aligned}
\int_{0}^{d\left(u, z_{n+1}\right)} \varphi(t) d t & =\int_{0}^{d\left(T u, T z_{n}\right)} \varphi(t) d t \\
& \leq \alpha\left(u, z_{n}\right) \int_{0}^{d\left(T u, T z_{n}\right)} \varphi(t) d t \\
& \leq \psi\left(\int_{0}^{N\left(u, z_{n}\right)} \varphi(t) d t\right),
\end{aligned}
$$


where

$$
\begin{aligned}
N\left(u, z_{n}\right) & =\max \left\{d\left(u, z_{n}\right), \frac{d(u, T u)+d\left(z_{n}, T z_{n}\right)}{2}\right\} \\
& =\max \left\{d\left(u, z_{n}\right), \frac{d\left(z_{n}, z_{n+1}\right)}{2}\right\} .
\end{aligned}
$$

By $(\mathrm{H} 2)$, we get

$$
N\left(u, z_{n}\right)=d\left(u, z_{n}\right) \quad \forall n .
$$

Iteratively, by using inequality (78), we get that

$$
\int_{0}^{d\left(u, z_{n}\right)} \varphi(t) d t \leq \psi^{n}\left(\int_{0}^{d\left(u, z_{0}\right)} \varphi(t) d t\right),
$$

for all $n$. Letting $n \rightarrow \infty$ in the above inequality, we obtain

$$
\lim _{n \rightarrow \infty} \int_{0}^{d\left(z_{n}, u\right)} \varphi(t) d t=0,
$$

and hence

$$
\lim _{n \rightarrow \infty} d\left(z_{n}, u\right)=0
$$

Analogously, one can show that

$$
\lim _{n \rightarrow \infty} d\left(z_{n}, v\right)=0 \text {. }
$$

Similarly, regarding (W) together with (83) and (84), it follows that $u=v$. Thus we proved that $u$ is the unique fixed point of $T$.

It is known that Hausdorffness property implies the uniqueness of the limit, so the (W) condition in Theorem 22 (resp., Theorem 23) can be replaced by Hausdorff property. Then, the proof of the following result is clear and hence it is omitted.

Corollary 24. Adding conditions (H1) and (H2) to the hypotheses of Theorem 16 (resp., Theorems 18, 17, and 19) and assuming that $(X, d)$ is Hausdorff, one obtains that $u$ is the unique fixed point of $T$.

\section{Consequences}

In what follows we introduce the notion of $\alpha-\psi$-contractive type mappings of integral type.

Definition 25 (Karapınar, [14]). Let $(X, d)$ be a generalized metric space and let $T: X \rightarrow X$ be a given mapping. One says that $T$ is an $\alpha-\psi$-contractive mapping of integral type if there exist two functions $\alpha: X \times X \rightarrow[0,+\infty)$ and $\psi \in \Psi$ such that for each $x, y \in X$

$$
\alpha(x, y) \int_{0}^{d(T x, T y)} \varphi(t) d t \leq \psi\left(\int_{0}^{d(x, y)} \varphi(t) d t\right)
$$

where $\varphi \in \Phi_{s}$.

Now, we state the following fixed point theorem.
Theorem 26 (Karapınar, [14]). Let $(X, d)$ be a complete generalized metric space and let $T: X \rightarrow X$ be an $\alpha-\psi$ contractive mapping of integral type. Suppose that

(i) $T$ is $\alpha$-admissible;

(ii) there exists $x_{0} \in X$ such that $\alpha\left(x_{0}, T x_{0}\right) \geq 1$ and $\alpha\left(x_{0}, T^{2} x_{0}\right) \geq 1$

(iii) either $T$ is continuous or $\left\{x_{n}\right\}$ is regular.

Then there exists a $u \in X$ such that $T u=u$.

Proof. The proof is verbatim of the proofs of Theorems 16 and 18.

Theorem 27 (Karapinar, [14]). Adding condition $(U)$ to the hypotheses of Theorem 26, one obtains that $u$ is the unique fixed point of $T$.

Proof. The proof is verbatim of the proofs of Theorem 20.

Remark 28. The uniqueness condition $(U)$ in Theorem 27 can be replaced with alternative criteria (H1), (H2), and (W) as in Theorems 22 and 23.

Corollary 29. Let $(X, d)$ be a complete generalized metric space and let $T: X \rightarrow X$ be a continuous mapping. Suppose that there exists a function $\psi \in \Psi$ such that

$$
\int_{0}^{d(T x, T y)} \varphi(t) d t \leq \psi\left(\int_{0}^{M(x, y)} \varphi(t) d t\right),
$$

for all $x, y \in X$, where $\varphi \in \Phi_{s}$ and

$$
M(x, y)=\max \{d(x, y), d(x, T x), d(y, T y)\} .
$$

Then T has a unique fixed point.

Proof. Let $\alpha: X \times X \rightarrow[0, \infty)$ be the mapping defined by $\alpha(x, y)=1$, for all $x, y \in X$. Then $T$ is an $\alpha-\psi$-contraction mapping of integral type I. It is clear that all conditions of Theorem 20 are satisfied. Hence, $T$ has a unique fixed point.

Corollary 30. Let $(X, d)$ be a complete generalized metric space and let $T: X \rightarrow X$ be a continuous mapping. Suppose that there exists a function $\psi \in \Psi$ such that

$$
\int_{0}^{d(T x, T y)} \varphi(t) d t \leq \psi\left(\int_{0}^{N(x, y)} \varphi(t) d t\right),
$$

for all $x, y \in X$, where $\varphi \in \Phi_{s}$ and

$$
N(x, y)=\max \left\{d(x, y), \frac{d(x, T x)+d(y, T y)}{2}\right\} .
$$

Then T has a unique fixed point.

Proof. As in the corollary, it is sufficient to define $\alpha: X \times X \rightarrow$ $[0, \infty)$ such that $\alpha(x, y)=1$, for all $x, y \in X$. Then, evidently, $T$ is an $\alpha-\psi$-contraction mapping of integral type II. Hence, all conditions of Theorem 21 are fulfilled. So, $T$ has a unique fixed point. 
The following fixed point theorems follow immediately from Corollary 29 by taking $\psi(t)=\lambda t$, where $\lambda \in(0,1)$.

Corollary 31. Let $(X, d)$ be a complete generalized metric space and let $T: X \rightarrow X$ be a continuous mapping. Suppose that there exists a constant $\lambda \in(0,1)$ such that

$$
\int_{0}^{d(T x, T y)} \varphi(t) d t \leq \lambda \int_{0}^{M(x, y)} \varphi(t) d t,
$$

for all $x, y \in X$, where $\varphi \in \Phi_{s}$ and

$$
M(x, y)=\max \{d(x, y), d(x, T x), d(y, T y)\} .
$$

Then $T$ has a unique fixed point.

By taking $\psi(t)=\lambda t$, where $\lambda \in(0,1)$, in Corollary 30, we derive the following result.

Corollary 32. Let $(X, d)$ be a complete generalized metric space and let $T: X \rightarrow X$ be a continuous mapping. Suppose that there exists a constant $\lambda \in(0,1)$ such that

$$
\int_{0}^{d(T x, T y)} \varphi(t) d t \leq \lambda \int_{0}^{N(x, y)} \varphi(t) d t
$$

for all $x, y \in X$, where $\varphi \in \Phi_{s}$ and

$$
N(x, y)=\max \left\{d(x, y), \frac{d(x, T x)+d(y, T y)}{2}\right\} .
$$

Then T has a unique fixed point.

Corollary 33 (cf. [11]). Let $(X, d)$ be a complete generalized metric space and let $T: X \rightarrow X$ be a continuous mapping. Suppose that there exists a function $\psi \in \Psi$ such that

$$
d(T x, T y) \leq \psi(M(x, y)),
$$

for all $x, y \in X$. Then $T$ has a unique fixed point.

Proof. Let $\alpha: X \times X \rightarrow[0, \infty)$ be the mapping defined by $\alpha(x, y)=1$, for all $x, y \in X$. Then $T$ is an $\alpha-\psi$-contraction mapping. It is evident that all conditions of Theorem 8 are satisfied. Hence, $T$ has a unique fixed point.

The following fixed point theorems follow immediately from Corollary 33 by taking $\psi(t)=\lambda t$, where $\lambda \in(0,1)$.

Corollary 34 (see e.g. [11]). Let $(X, d)$ be a complete generalized metric space and let $T: X \rightarrow X$ be a continuous mapping. Suppose that there exists a constant $\lambda \in(0,1)$ such that

$$
d(T x, T y) \leq \lambda N(x, y),
$$

for all $x, y \in X$. Then $T$ has a unique fixed point.

Now, we will show that many existing results in the literature can be deduced easily from our obtained results. The following theorems are the main results of Aydi et al. [11].

Theorem 35 (Aydi et al. [11]). Let $(X, d)$ be a complete generalized metric space and let $T: X \rightarrow X$ be a generalized $\alpha-\psi$ contractive mapping of type I. Suppose that

(i) $T$ is $\alpha$-admissible; (ii) there exists $x_{0} \in X$ such that $\alpha\left(x_{0}, T x_{0}\right) \geq 1$ and $\alpha\left(x_{0}, T^{2} x_{0}\right) \geq 1$

(iii) either $T$ is continuous or if $\left\{x_{n}\right\}$ is a sequence in $X$ such that $\alpha\left(x_{n}, x_{n+1}\right) \geq 1$ for all $n$ and $x_{n} \rightarrow x \in X$ as $n \rightarrow \infty$, then there exists a subsequence $\left\{x_{n(k)}\right\}$ of $\left\{x_{n}\right\}$ such that $\alpha\left(x_{n(k)}, x\right) \geq 1$ for all $k$.

Then there exists $a u \in X$ such that $T u=u$.

Proof. It is sufficient to take $\varphi(t)=1$ in Theorems 16 and 18 .

Theorem 36 (Aydi et al. [11]). Let $(X, d)$ be a complete generalized metric space and let $T: X \rightarrow X$ be a generalized $\alpha-\psi$ contractive mapping of type II. Suppose that

(i) $T$ is $\alpha$-admissible;

(ii) there exists $x_{0} \in X$ such that $\alpha\left(x_{0}, T x_{0}\right) \geq 1$ and $\alpha\left(x_{0}, T^{2} x_{0}\right) \geq 1$

(iii) either $T$ is continuous or if $\left\{x_{n}\right\}$ is a sequence in $X$ such that $\alpha\left(x_{n}, x_{n+1}\right) \geq 1$ for all $n$ and $x_{n} \rightarrow x \in X$ as $n \rightarrow \infty$, then there exists a subsequence $\left\{x_{n(k)}\right\}$ of $\left\{x_{n}\right\}$ such that $\alpha\left(x_{n(k)}, x\right) \geq 1$ for all $k$.

Then there exists a $u \in X$ such that $T u=u$.

Proof. If we take $\varphi(t)=1$ in Theorems 17 and 19, then the proof follows immediately.

Theorem 37 (Aydi et al. [11]). Adding condition $(U)$ to the hypotheses of Theorem 35 (resp., Theorem 36), one obtains that $u$ is the unique fixed point of $T$.

Proof. Let $\varphi(t)=1$ in Theorems 20 and 21 .

Remark 38. Notice that all consequences and corollaries of Aydi et al. [11] can be added here since their main results are corollaries of the main results of this paper. To avoid the repetition, we do not want to state them here but we underline this fact.

Example 39. Let $X=[0,1]$ and $A=\{1 / n: n \in \mathbb{N}\}$. We define the distance function $d: X \times X \rightarrow[0, \infty)$ as follows:

$$
\begin{aligned}
& d(x, y)=0 \quad \text { if } x=y, \\
& d(x, y)=d(y, x) \quad \forall x, y, \\
& d\left(\frac{1}{2}, \frac{1}{3}\right)=d\left(\frac{1}{4}, \frac{1}{5}\right)=\frac{1}{5}, \\
& d\left(\frac{1}{2}, \frac{1}{5}\right)=d\left(\frac{1}{3}, \frac{1}{4}\right)=\frac{2}{5}, \\
& d\left(\frac{1}{2}, \frac{1}{4}\right)=d\left(\frac{1}{3}, \frac{1}{5}\right)=1, \\
& d(x, y)=|x-y| \quad \text { otherwise. }
\end{aligned}
$$

It is clear that $(X, d)$ is a generalized metric space. Notice also that $d$ is not a metric since

$$
1=d\left(\frac{1}{2}, \frac{1}{4}\right)>d\left(\frac{1}{2}, \frac{1}{3}\right)+d\left(\frac{1}{3}, \frac{1}{4}\right)=\frac{3}{5} .
$$


We define $T: X \rightarrow X$ as $T x=1-x$. Furthermore, let $\psi:[0, \infty) \rightarrow[0, \infty)$ be defined as $\psi(t)=t / 3$ and $\varphi(t)=1$. Now, we define $\alpha X \times X \rightarrow[0, \infty)$ as follows:

$$
\alpha(x, y)= \begin{cases}1 & \text { if } x=y \\ 5 x & \text { if } x, y \in\left\{\frac{1}{2}, \frac{1}{3}, \frac{1}{4}, \frac{1}{5}\right\} \text { with } x \neq y \\ 0 & \text { otherwise. }\end{cases}
$$

Hence, all conditions of Theorem 20 are satisfied and $x=1 / 2$ is a unique fixed point of $T$.

\section{Conflict of Interests}

The author declares that there is no conflict of interests regarding the publication of this paper.

\section{Acknowledgment}

The author thanks the anonymous referees for their remarkable comments, suggestions, and ideas that helped the author to improve this paper.

\section{References}

[1] A. Branciari, "A fixed point theorem of Banach-Caccioppoli type on a class of generalized metric spaces," Publicationes Mathematicae Debrecen, vol. 57, no. 1-2, pp. 31-37, 2000.

[2] H. Aydi, E. Karapinar, and H. Lakzian, "Fixed point results on a class of generalized metric spaces," Mathematical Sciences, vol. 6, article 46, 2012.

[3] A. Azam and M. Arshad, "Kannan fixed point theorem on generalized metric spaces," Journal of Nonlinear Sciences and Its Applications, vol. 1, no. 1, pp. 45-48, 2008.

[4] A. Azam, M. Arshad, and I. Beg, "Banach contraction principle on cone rectangular metric spaces," Applicable Analysis and Discrete Mathematics, vol. 3, no. 2, pp. 236-241, 2009.

[5] N. Bilgili and E. Karapınar, "Common fixed points for $(\psi, \alpha, \beta)$ weakly contractive mappings in generalized metric spaces," Fixed Point Theory and Applications, vol. 2013, article 287, 2013.

[6] P. Das, "A fixed point theorem on a class of generalized metric spaces," Korean Journal of Mathematical Sciences, vol. 9, pp. 2933, 2002.

[7] P. Das, "A fixed point theorem in a generalized metric space," Soochow Journal of Mathematics, vol. 33, no. 1, pp. 33-39, 2007.

[8] P. Das and B. K. Lahiri, "Fixed point of a Ljubomir Ciric's quasi-contraction mapping in a generalized metric space," Publicationes Mathematicae Debrecen, vol. 61, pp. 589-594, 2002.

[9] P. Das and L. K. Dey, "Fixed point of contractive mappings in generalized metric spaces," Mathematica Slovaca, vol. 59, no. 4, pp. 499-504, 2009.

[10] I. M. Erhan, E. Karapınar, and T. Sekulic, "Fixed points of $(\psi, \phi)$ contractions on rectangular metric spaces," Fixed Point Theory and Applications, vol. 2012, article 138, 2012.

[11] H. Aydi, E. Karapınar, and B. Samet, "Fixed points for generalized $(\alpha, \psi)$-contractions on generalized metric spaces," Journal of Inequalities and Applications, vol. 2014, article 229, 2014.

[12] M. Jleli and B. Samet, "The Kannan's fixed point theorem in a cone rectangular metric space," Journal of Nonlinear Science and its Applications, vol. 2, no. 3, pp. 161-167, 2009.
[13] E. Karapınar, "Discussion on $(\alpha, \psi)$ contractions on generalized metric spaces," Abstract and Applied Analysis, vol. 2014, Article ID 962784, 7 pages, 2014.

[14] E. Karapinar, "Current trends in analysis and its applications," in Proceedings of the 9th ISAAC Congress, V. Mityushev and M. Ruzhanslcy, Eds., Springer, Krakow, Poland, 2013.

[15] E. Karapinar and B. Samet, "Generalized $\alpha-\psi$-contractive type mappings and related fixed point theorems with applications," Abstract and Applied Analysis, vol. 2012, Article ID 793486, 17 pages, 2012.

[16] L. Kikina and K. Kikina, "A fixed point theorem in generalized metric spaces," Demonstratio Mathematica, vol. 46, no. 1, pp. 181-190, 2013.

[17] H. Lakzian and B. Samet, "Fixed points for $(\psi, \varphi)$-weakly contractive mappings in generalized metric spaces," Applied Mathematics Letters, vol. 25, no. 5, pp. 902-906, 2012.

[18] D. Mihet, "On Kannan fixed point principle in generalized metric spaces," Journal of Nonlinear Science and its Applications, vol. 2, no. 2, pp. 92-96, 2009.

[19] C. M. Ming and C. H. Chen, "Periodic points for the weak contraction mappings in complete generalized metric spaces," Fixed Point Theory and Applications, vol. 2012, article 79, 2012.

[20] B. Samet, "Discussion on "a fixed point theorem of BanachCaccioppoli type on a class of generalized metric spaces" by A. Branciari," Publicationes Mathematicae Debrecen, vol. 76, no. 4, Article ID 493494, pp. 493-494, 2010.

[21] W. Shatanawi, A. Al-Rawashdeh, H. Aydi, and H. K. Nashine, "On a fixed point for generalized contractions in generalized metric spaces," Abstract and Applied Analysis, vol. 2012, Article ID 246085, 13 pages, 2012.

[22] B. Samet, C. Vetro, and P. Vetro, "Fixed point theorems for $\alpha-\psi$-contractive type mappings," Nonlinear Analysis: Theory, Methods \&; Applications, vol. 75, no. 4, pp. 2154-2165, 2012.

[23] M. U. Ali and T. Kamran, "On $\left(\alpha^{*}, \psi\right)$-contractive multi-valued mappings," Fixed Point Theory and Applications, vol. 2013, article 137, 2013.

[24] M. Jleli, E. Karapınar, and B. Samet, "Best proximity points for generalized $\alpha$ - $\psi$-proximal contractive type mappings," Journal of Applied Mathematics, vol. 2013, Article ID 534127, 10 pages, 2013.

[25] M. Jleli, E. Karapınar, and B. Samet, "Fixed point results for $\alpha$ $\psi_{\lambda}$ contractions on gauge spaces and applications," Abstract and Applied Analysis, vol. 2013, Article ID 730825, 7 pages, 2013.

[26] B. Mohammadi, S. Rezapour, and N. Shahzad, "Some results on fixed points of $(\alpha-\psi)$-Ciric generalized multifunctions," Fixed Point Theory and Applications, vol. 2013, article 24, 2013.

[27] W. A. Wilson, "On semi-metric spaces," American Journal of Mathematics, vol. 53, no. 2, pp. 361-373, 1931.

[28] W. A. Kirk and N. Shahzad, "Generalized metrics and Caristi's theorem," Fixed Point Theory and Applications, vol. 2013, article 129, 2013.

[29] M. U. Ali, T. Kamran, and E. Karapınar, "An approach to existence of fixed po ints of generalized contractive multivalued mappings of integral type via admissible mapping," Abstract and Applied Analysis, vol. 2014, Article ID 141489, 7 pages, 2014. 


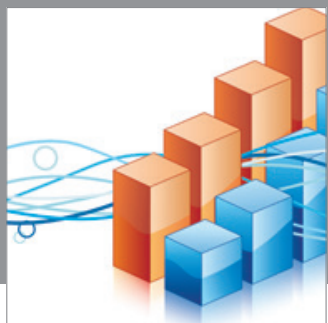

Advances in

Operations Research

mansans

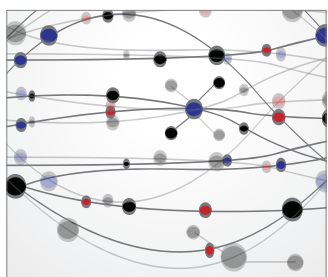

The Scientific World Journal
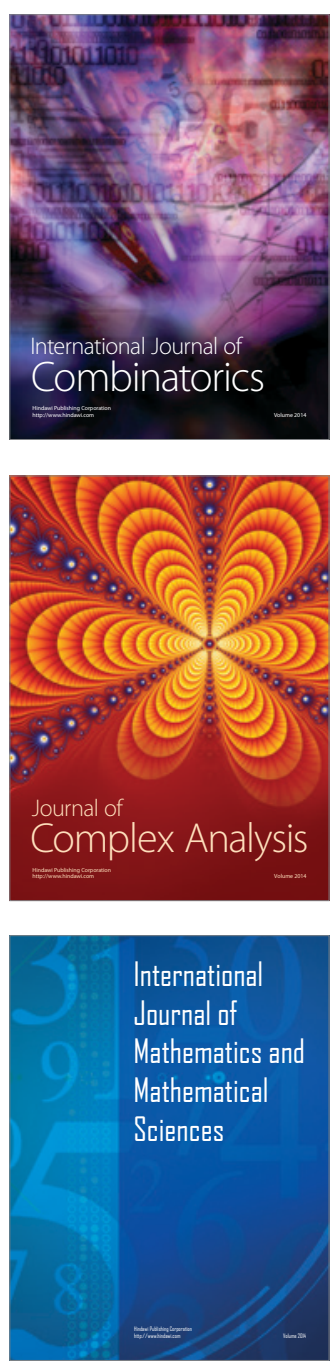
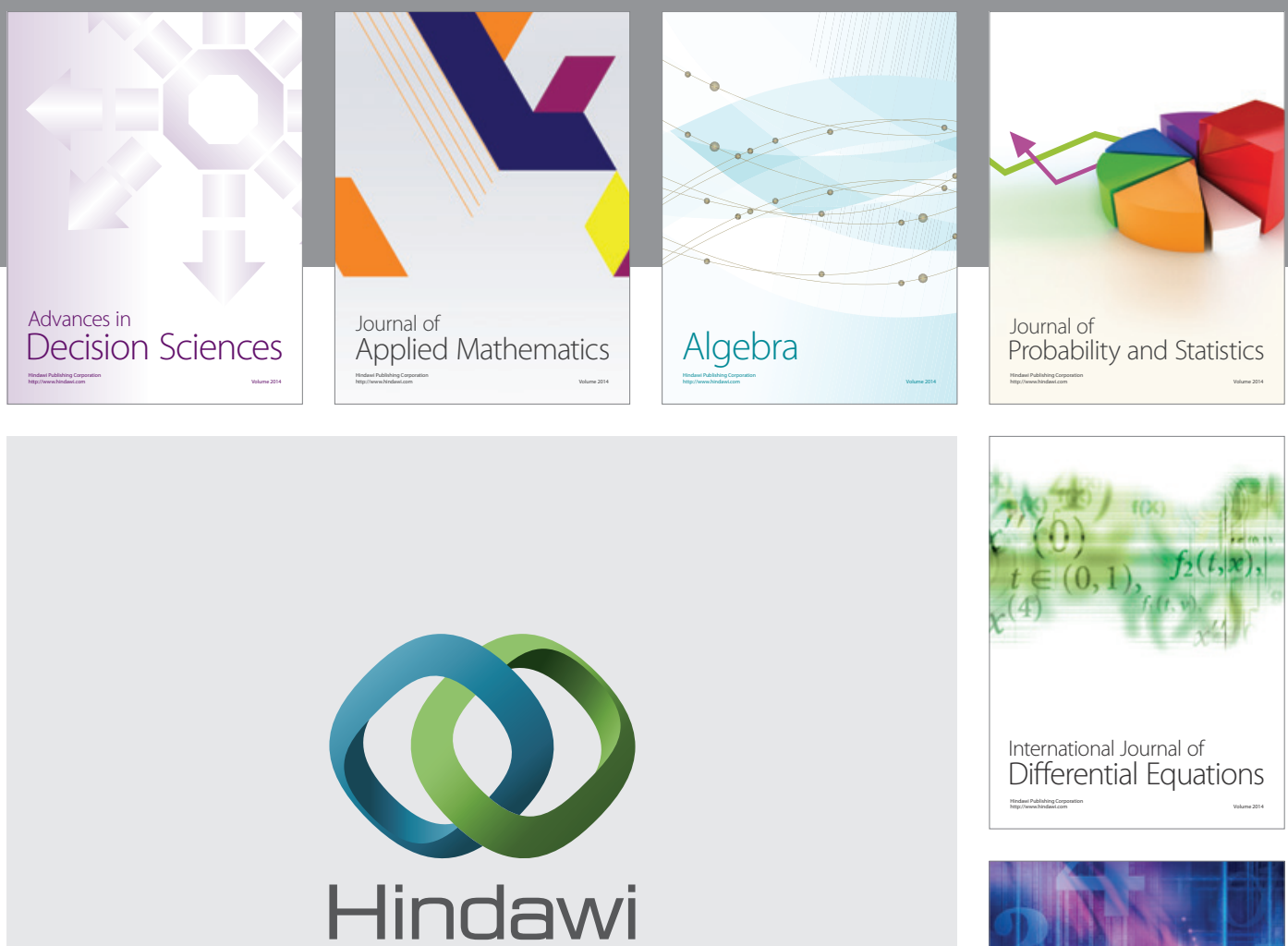

Submit your manuscripts at http://www.hindawi.com
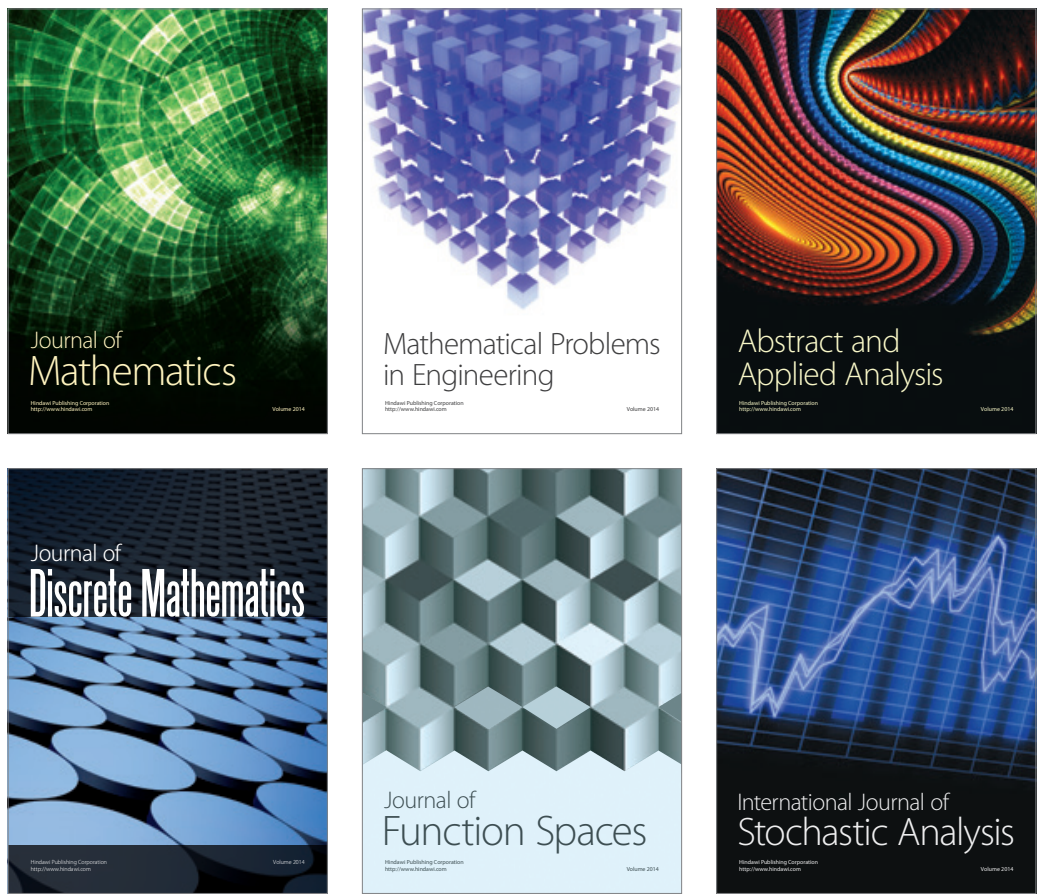

Journal of

Function Spaces

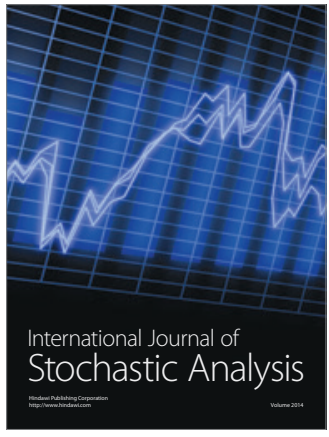

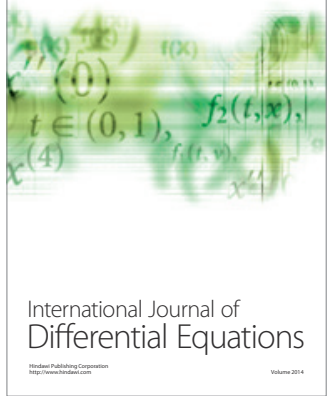
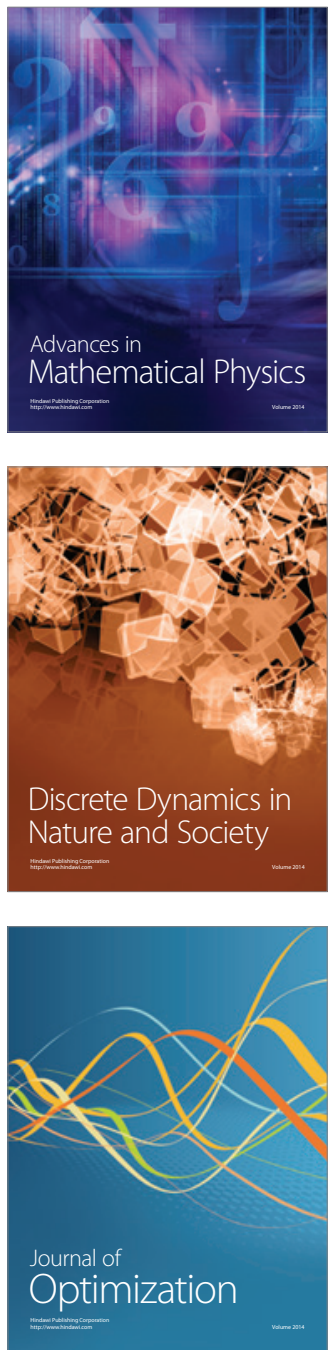